\title{
INFLUENCE OF LIGHT ON STRUCTURE OF AMORPHOUS SELENIUM LAYERS
}

\author{
E. Montrimas, R. Rinkūnas, S. Kuskevičius, and R. Purlys \\ Faculty of Physics, Vilnius University, Sauletekio 9, LT-10222 Vilnius, Lithuania \\ E-mail: ringaudas.rinkunas@ff.vu.lt
}

Received 6 June 2007; revised 4 July 2008; accepted 18 September 2008

\begin{abstract}
After exposure of amorphous selenium islands to luminous flux of $1 \cdot 10^{6} \mathrm{~lx}$, they do not become crystalline, but remain amorphous. However, light stimulates polymerization of molecules in those islands. For this reason, heating of a layer that is exposed to light does not cause a decrease of the mean thickness of the layer, but heating of the layer in the dark causes a decrease of its mean thickness. Therefore, the mean thickness of the illuminated layer is 3 to 4 times greater than the mean thickness of the layer in the dark. In addition, the fraction of the substrate covered by the islands is 1.5 to 2 times larger in the exposed layer than in the unexposed layer. However, illumination of a continuous layer speeds up its transformation into an island-type layer. Therefore, in order to obtain an extremely thin continuous layer of amorphous selenium, during growth of the layer it must be exposed to light only until it becomes continuous. Starting from that moment, the light must be switched off.
\end{abstract}

Keywords: thin film, selenium, island, polymer

PACS: 68.37.-d, 68.43.Jk, 68.55.Ac

\section{Introduction}

Properties of polymer layers are strongly dependent on the length of polymer chains of the layer [1]. If the layers are formed from the solution, then the polymer chains are formed during removal of the solvent from the bulk of the layer. In such a case the polymer chain length depends on composition of the material from which the layers are formed, on solvent evaporation rate, on ambient temperature, and other technological conditions. If the materials are evaporated in vacuum (those can be organic materials, too), then the length of molecules leaving the crucible cannot be very large, because of a low probability of such an event. The deposited layers do not contain solvents, which have a significant influence on layer polymerization. Therefore, it is simpler to investigate layers deposited in vacuum [2], because there are less technological conditions that influence layer formation.

Growth of polymer layers is different from, e.g., growth of metallic layers, because molecules deposited from gaseous phase onto the substrate have a tendency to form polymer chains. However, those chains are not stable enough to serve as a nucleus. Such a chain can continue migrating along the surface of the substrate [3]. However, motion of a chain is more constrained than motion of single atoms. Therefore, immediately after deposition of a polymer layer, a large quantity of adsorbed mobile polymer gas exists on the surface of the substrate. That gas is formed of molecules linked into polymer chains (it is a chain of atoms, rather than a separate atom, that evaporates from the crucible [4]). In addition, several islands already exist on the substrate at that time [5]. In polymer layers, an island forms only after linking together a rather large number of polymer molecules. The future evolution of such an island depends on the quantity of adsorbed gas between the islands, size of the island, and temperature of the substrate [5].

Amorphous selenium is formed of selenium atoms linked into chains. If we replace selenium atoms with carbon atoms, we would obtain a typical organic molecule. Motion of this large organic molecule along the surface of the substrate would be also more impeded than motion of individual carbon atoms. Hence, the observed regularities for amorphous polymer selenium layers may be similar to regularities of growth of organic layers. Using a transmission-type electronic microscope, it is easier to investigate thin polymeric selenium layers than organic layers, because selenium atoms are relatively heavy and they scatter electrons 
more effectively than light carbon atoms - hence it is possible to observe the structure of selenium layers.

During manufacture of layers (especially organic layers), it is desirable to prepare continuous layers of minimum possible thickness. A continuous layer is obtained when islands merge with each other. In such a case, the covered fraction of the substrate is $100 \%$. However, the method used to obtain the covered fraction of $100 \%$ is also important - it is possible that a certain method allows covering the substrate completely with a thinner layer than other technological conditions. Investigation of the role of various technological conditions in the growth of a layer is difficult, because the growing layer changes all the time. However, for example, influence of light on the layer structure may be different in different areas of the layer. In such a case, it is not clear at which stage of layer growth the light should be switched on, switched off, or attenuated. However, layer growth can be "frozen" at various stages, allowing to investigate influence of, e. g., light on layer structure at a particular stage. In this work, we have investigated influence of light on amorphous selenium layers with varying thickness after deposition of those layers. We think that similar influence of light would be also observed during layer growth. This work studies influence of light on the filling level of island-type and continuous amorphous selenium layers. After determining the influence of light on layer structure, it would be possible to obtain a layer with desirable structure during its deposition or after the deposition.

\section{Methods}

Amorphous island-type selenium layers were deposited upon glass substrate. The samples were prepared in vacuum at a pressure of $10^{-4}$ torr by selenium evaporation from a directly heated tungsten trough. The process of evaporation from the trough is observed visually. When the material in the evaporator heats up and evaporation begins, the damper between the evaporator and the substrate is opened. After the end of evaporation, this damper is closed in order to avoid further heating of the evaporated layer by the evaporator. Prior to evaporation, a known mass of evaporated material is placed into the tungsten trough. If this mass is sufficiently large, continuous layers are obtained. Substrate temperature is stabilized using a water thermostat. The samples were prepared at substrate temperature of $20^{\circ} \mathrm{C}$. At this substrate temperature, the polymer selenium chains are shorter than at a higher temperature (such layers crystallize easily [6], because their molecules are more mobile and they are more likely to rearrange into a stable structure - crystals). To increase the mobility of molecules and to prevent the crystallization of layers, prepared layers were heated to $60^{\circ} \mathrm{C}$ temperature. Specimens were investigated in transmission electron microscope EMV-100.

The light can heat the layer. In order to avoid that, thermal radiation was removed from the light flux using special filters. Exposure of a thermometer or a thermocouple to filtered light caused only a 0.3 degree change of their temperature in an hour. However, the layer may be heated to a higher temperature than the substrate. We checked for that effect using thermocouples deposited upon the glass (thermocouples were formed from copper and constantan; afterwards, this film-type thermocouple was calibrated). In one case, an amorphous selenium layer was deposited upon the film thermocouple. In all cases, the temperature increase after exposing the thermocouple to white light with intensity of $1 \cdot 10^{6} \mathrm{~lx}$ did not exceed $0.2-0.5^{\circ} \mathrm{C}$. In addition, the increase of temperature after illumination was measured using a infrared thermometer EMSiTest IR-8839. In this case, the change of temperature did not exceed $0.7-0.9^{\circ} \mathrm{C}$. Besides, a very abrupt change of layer structure when passing the shadow boundary, has been observed (a part of the layer was illuminated through a mask, which cast a sharp shadow). If such a change were caused by a change of layer temperature, the temperature gradient would have to be $1 \cdot 10^{6}{ }^{\circ} \mathrm{C} / \mathrm{m}$, which is impossible with a $2 \mathrm{~mm}$-thick substrate.

\section{Results}

This work deals with thin island-type layers (with 5-100 nm thickness) and continuous layers (with 0.7$5 \mu \mathrm{m}$ thickness). Island-type layers do not fill the entire surface of the substrate. During heating of islandtype layers, small islets disappear, whereas large ones grow [7]. Therefore, the substrate area covered by the layer should decrease continuously, and overall layer mass would remain constant until the layer begins to re-evaporate from the substrate [5] (total mass of the layer, including islands and gas, does not change until the layer begins evaporating). However, a part of the gas adsorbed on the layer surface during the layer heating migrates to the growing islets [5]; therefore the substrate filling fraction grows during heating (Fig. 1(b)). Particle density in the dark continuously decreases (Fig. 1(c), curve 2), while kinetics of particle density in illuminated region has a complicated character. The substrate fraction covered by the layer in- 


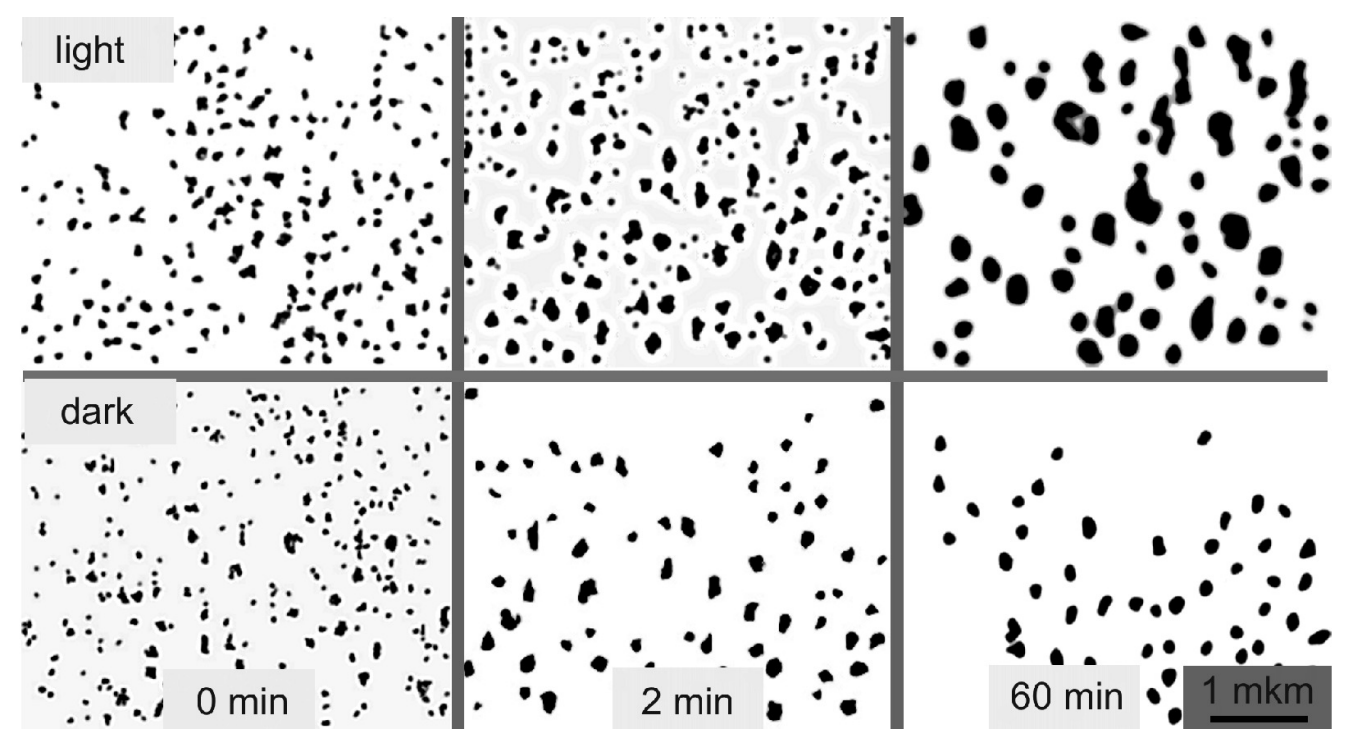

(a)

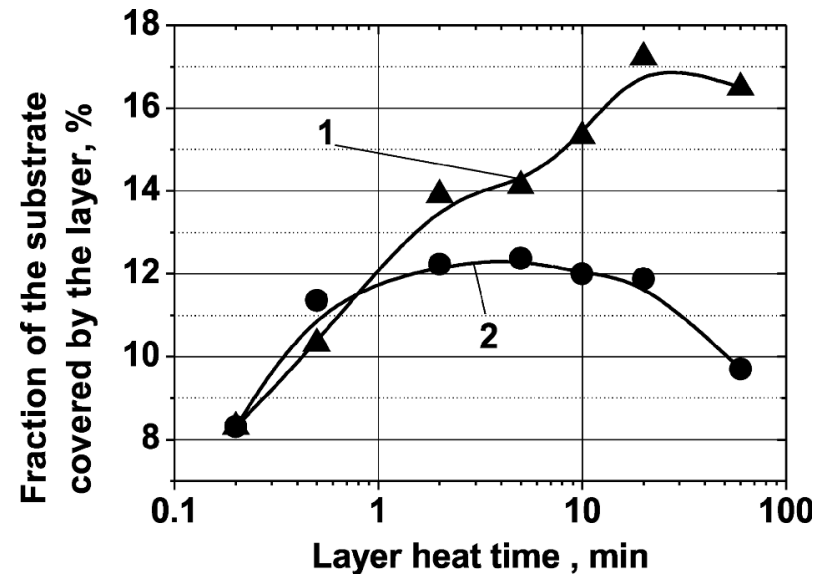

(b)

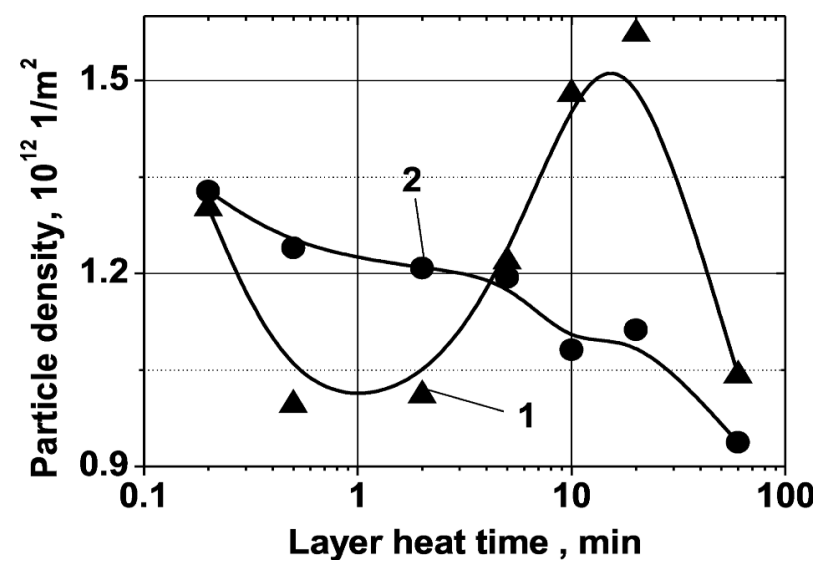

(c)

Fig. 1. (a) Photographs of amorphous selenium layer; dependence of (b) the substrate fraction covered by the layer and (c) particle density on the heating time at a $60^{\circ} \mathrm{C}$ temperature. Curve 1 for layer exposed to light with $1 \cdot 10^{6} \mathrm{~lx}$ intensity, 2 for layer in the dark. Thickness of the island-type layer is $5 \mathrm{~nm}$.

creases during almost entire time of exposure to light (Fig. 1(b), curve 1), whereas layer heating in the dark is characterized by the usual pattern: at first the substrate filling fraction of specimen in dark increases, and then it begins to decrease (Fig. 1(b), curve 2).

In the thicker layers the gas adsorbed on the layer surface during the layer heating also migrates to the growing islets or forms new islets (Fig. 2(c), curve 2); therefore the substrate filling fraction grows during heating (Fig. 2(b)). As the layer is heated further, the growing islands begin taking material from the smallest ones, instead of feeding on the adsorbed gas. In addition, a part of the layer material evaporates from the substrate surface. Therefore, the substrate filling fraction decreases. Exposure of the island layer to white light with intensity of $1 \cdot 10^{6} \mathrm{~lx}$ speeds up the merging of adsorbed gas into islands, but later on the mass exchange between islands speeds up, too (Fig. 2(c), curve 1: new islands are not created in illuminated layer and the density of existing islands is continuously decreased), as well as evaporation of the layer material from the substrate (Fig. 2(b), curve 1 ). The further character of curve 1 is somewhat unexpected - it would seem that action of light should speed up the decrease of substrate filling fraction in comparison with heating in the dark. However, experiments show that the fraction of the substrate surface covered by the islets stabilizes under illumination, whereas the filling fraction of the substrate heated in the dark continues to decrease (Fig. 2(b), curve 2).

Thin continuous layers are characterized by large surface tension forces, which tend to tear the layer into spherical pieces [8]. At a low temperature, the motion of polymer molecules is slow; hence in such layers formation of crystals is more likely than tearing due 


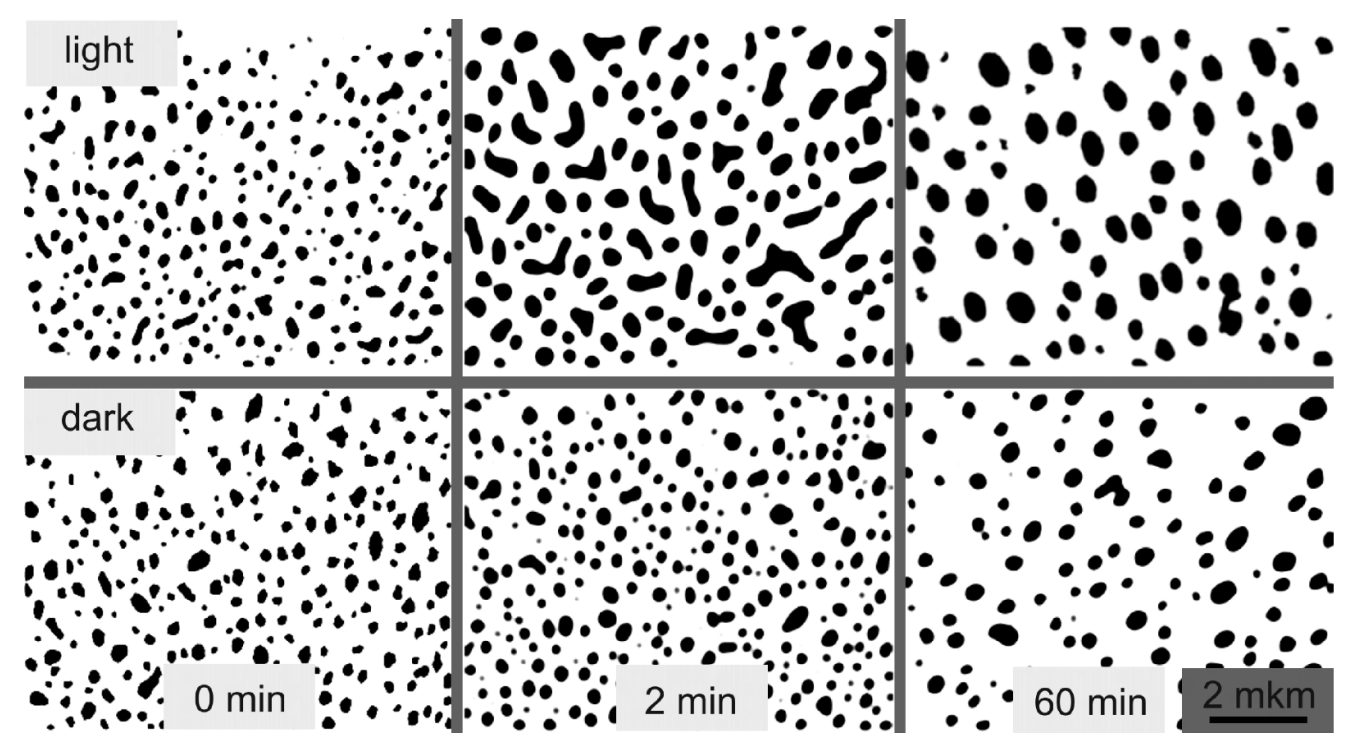

(a)

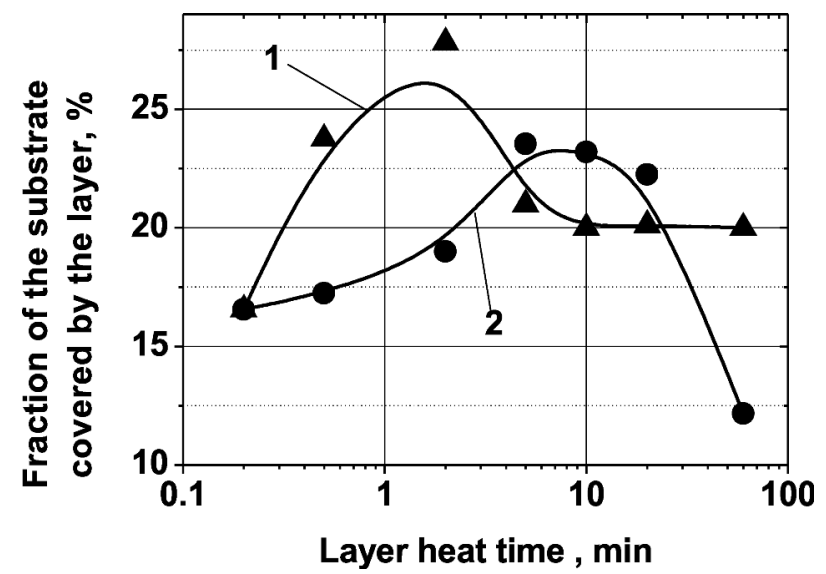

(b)

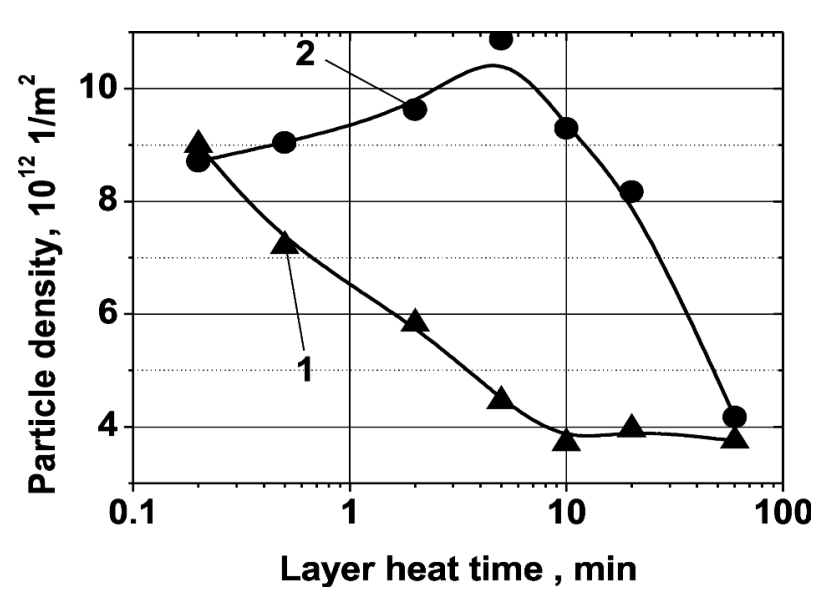

(c)

Fig. 2. (a) Photographs of amorphous selenium layer; dependence of (b) the substrate fraction covered by the layer and (c) particle density on the heating time at a $60^{\circ} \mathrm{C}$ temperature. Curve 1 for layer exposed to light with $1 \cdot 10^{6} \mathrm{~lx}$ intensity, 2 for layer in the dark. Thickness of the island-type layer is $24 \mathrm{~nm}$.

to surface tension. However, after heating the layer to, e.g., $60^{\circ} \mathrm{C}$, the latter process prevails (Fig. 3(a)). Those are well-known phenomena, but they do not provide information about any changes in the layer polymer structure during its heating. However, exposure of the layer to white light with intensity of $1 \cdot 10^{6} \mathrm{~lx}$ speeds up the formation of an island-type layer from a continuous one (Fig. 3(b), curve 1). In this case, at first holes appear in the layer, and a thickened ring forms around each of them (that ring is visible in photographs as a dark band surrounding the hole: Fig. 3(a)). Afterwards, those holes grow, merge, and finally the separate isolated islands form in the layer. During all those transformations, the total mass of the layer does not change, but the fraction of the substrate surface that is covered by the layer decreases. Therefore, in order to prepare an especially thin continuous layer, incident light must be switched off when the layer becomes continuous.

The presented results indicate that exposure to light can increase the covered fraction of the substrate, but it must be switched off when the layer becomes continuous (because illumination increases the rate of formation of holes in the layer). However, in some cases exposure must be switched off earlier - this depends on the layer deposition rate. In the case of fast deposition (e. g., $700 \mathrm{~nm} / \mathrm{min}$ ), as shown in Figs. 1(b) and 2(b), exposure to light increases the covered fraction of the substrate if the heating time is less than $1 \mathrm{~min}$. Therefore, in this case the light must not be switched off until the layer becomes continuous. However, if the layer deposition rate is only $5 \mathrm{~nm} / \mathrm{min}$, then the layer thickness will reach $24 \mathrm{~nm}$ in about $5 \mathrm{~min}$, whereas Fig. 2(b) shows that the covered fraction of the substrate begins 


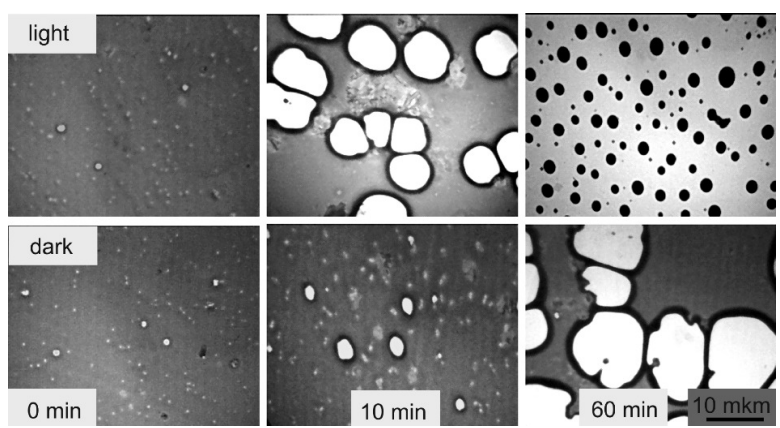

(a)

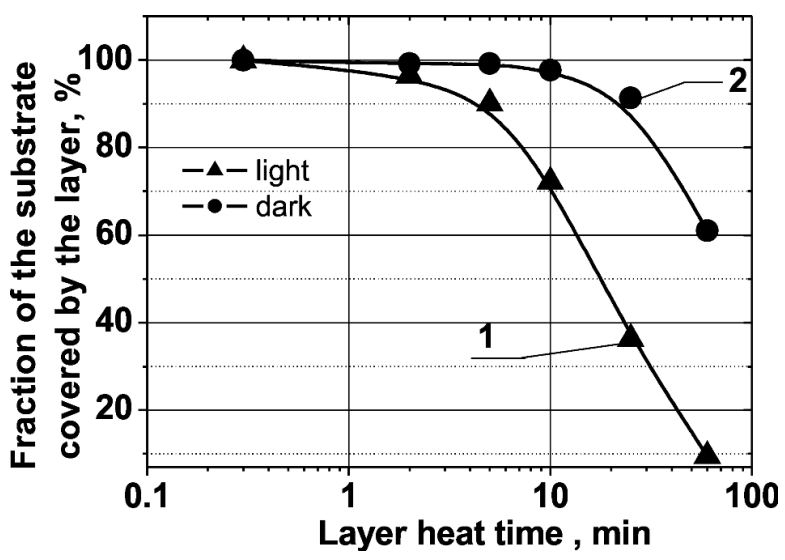

(b)

Fig. 3. (a) Photographs of amorphous selenium layer and (b) dependence of the substrate fraction covered by the layer on the heating time at a $60{ }^{\circ} \mathrm{C}$ temperature. Curve 1 for layer exposed to light with intensity of $1 \cdot 10^{6} \mathrm{~lx}, 2$ for layer in the dark. Thickness of continuous layer is $700 \mathrm{~nm}$.

decreasing after 2-3 min. Therefore, in this case the illumination of the growing layer should be switched off after 2-3 min. Of course, during deposition, the gas adsorbed on the substrate is constantly replenished with the gas coming from the evaporator. However, action of light on the gas that has just been deposited on the substrate and on the gas that had been present there earlier is the same.

The island-type amorphous selenium layers are composed of separate islands and adsorbed selenium molecules existing between the islands. Prior to discussing thickness of such a layer, one has to define "layer thickness". Layer thickness given in all figures has been determined from the calibration curve, which was obtained at a specific geometry of the vacuum equipment, using the measured amount of material evaporated from the crucible. This thickness depends on the total mass of the layer (including islands and adsorbed gas) and it does not change until the layer material starts evaporating from the substrate. If the term "layer" is applied only to stable islands, then layer thickness could be defined as, e.g., the maximum height of an island, or as thickness of a hypothetical continuous layer that would be obtained after spreading the entire mass of the islands evenly over the substrate. This thickness experiences significant variations over time after the layer deposition (Fig. 4), and its kinetics is similar to kinetics of the covered fraction of the layer (Figs. 4(a) and 1(b), 4(b) and 2(b)). The presented graphs indicate that thickness of a stable layer (contained in islands) can change up to 3 times (or 5-7 times in some particular cases [5]). A decrease of this thickness is most likely a result of partial evaporation of the layer material from the substrate. Such evaporation is especially pronounced in unexposed layers, and it begins earlier in thinner layers than in thicker ones (Fig. 4, curves 2). Thin layers do not lose mass after exposure to light (Fig. 4(a), curve 1). In thicker layers, action of light also helps to localize adsorbed molecules of gas in the growing islands (Fig. 4(b), curve 1), but after 2-3 min a part of the layer material is lost. Later on, layer thickness stabilizes and stops decreasing. Therefore, after illuminating a growing thin layer, evaporation of the layer material is less pronounced and a continuous layer is obtained more quickly.

\section{Discussion}

The goal of this work was investigation of influence of light on island-type selenium layers. As shown in the description of investigation techniques, the integral change of the temperature of the layer and substrate after exposure of the layer to $1 \cdot 10^{6} \mathrm{~lx}$ luminous flux did not exceed $0.2-0.9^{\circ} \mathrm{C}$ (temperature was measured using several different methods). However, temperature of individual islands is not known. Therefore, it is important to determine if light can change temperature of individual islands, because a change of temperature of an island by as much as 20 or 30 degrees would also contribute to the observed changes of layer structure (in addition to changes caused by action of light).

The temperature of an island increases as it absorbs energy of incident luminous flux. Hence, it is necessary to know the energy flux absorbed by, e. g., $1 \mu \mathrm{m}$ cubeshaped selenium island exposed to $1 \cdot 10^{6} \mathrm{~lx}$ luminous flux. The luminous flux (or visible energy) in a light source is defined by the photopic luminosity function [9]. The following equation defines the total luminous flux $F$ in a source of light:

$$
F=683.002 \int_{0}^{\infty} \hbar y(\lambda) J(\lambda) \mathrm{d} \lambda \quad\left[\mathrm{lx} /\left(\mathrm{W} / \mathrm{m}^{2}\right)\right],
$$




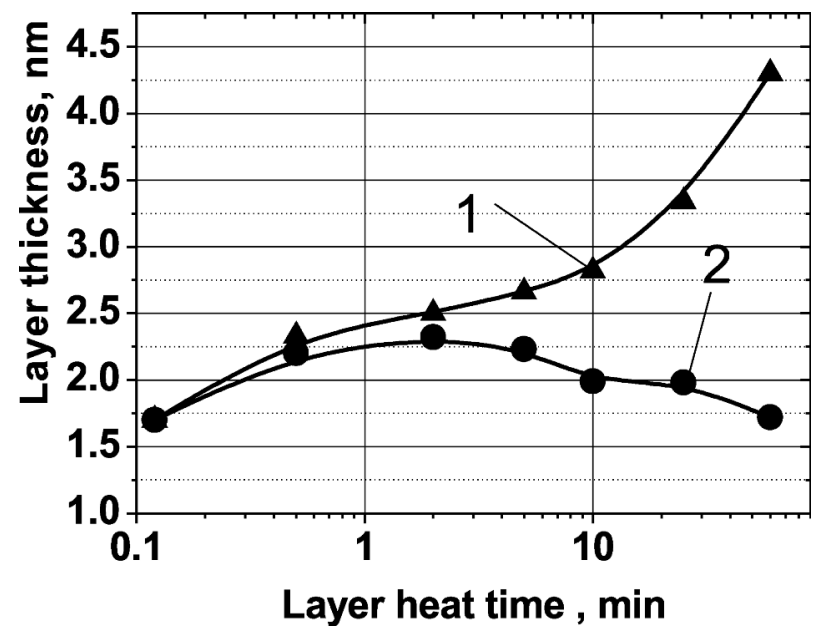

(a)

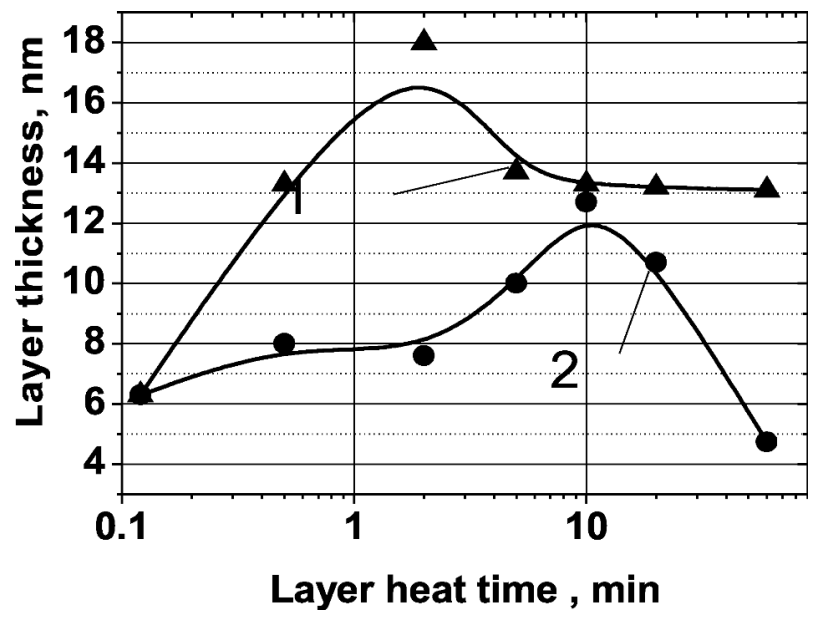

(b)

Fig. 4. Dependence of the average layer thickness (calculated from the total mass of the islands) on the heating time at $60{ }^{\circ} \mathrm{C}$ temperature. Layer thickness estimated from evaporated material mass: (a) $5 \mathrm{~nm}$, (b) $24 \mathrm{~nm}$. Curve 1 for layer exposed to light with intensity of $1 \cdot 10^{6} 1 \mathrm{x}$, 2 for layer in the dark.

where $F$ is the luminous flux in $\mathrm{lx}, J(\lambda)$ is the power spectral density of the radiation, in watts per unit wavelength per square metre, $\hbar y(\lambda)$ is the standard luminosity function (which is dimensionless).

This formula shows that measurement of luminous flux in units of lx does not, in general, allow estimation of energy flux (in units of $\mathrm{W} / \mathrm{m}^{2}$ ) incident on a given surface, because standard luminosity function in only non-zero in the wavelength range of 400-600 nm (this is because the unit lx is defined with the purpose of measuring only the contribution of light visible to a human eye). Therefore, contribution of light with other wavelengths is not taken into account when expressing the luminous flux in lx. However, amorphous selenium does not absorb light with wavelengths longer than $600 \mathrm{~nm} \mathrm{[10]} \mathrm{(besides,} \mathrm{wavelengths} \mathrm{longer} \mathrm{than}$ $600 \mathrm{~nm}$ have been eliminated by the light filter used in our work). Wavelengths shorter than $400 \mathrm{~nm}$ were also practically absent in the spectrum of our light source, because that light source was a halogen lamp, whose spectrum is similar to spectrum of black body radiation. Therefore, in our case the investigated wavelength range was practically the same as that used in the definition of the unit lx. Consequently, it is possible to estimate energy flux incident on the selenium layer exposed to a $1 \cdot 10^{6} \mathrm{~lx}$ luminous flux. Function is almost linearly increasing from 0 to 1 in the wavelength range of 400-500 nm and almost linearly decreasing from 1 to 0 in the wavelength range of $500-600 \mathrm{~nm}$. Hence, approximate estimate can be obtained by using its average value 0.5 . In such a case, the following value of energy flux $E$ of light incident on the layer is obtained from Eq. (1):

$$
E=\int_{0}^{\infty} J(\lambda) \mathrm{d} \lambda=F[\mathrm{~lx}] /(683.002 \cdot 0.5) \quad\left[\mathrm{W} / \mathrm{m}^{2}\right] .
$$

If $F=1 \cdot 10^{6} \mathrm{~lx}$, then Eq. (2) gives $E \approx 3000 \mathrm{~W} / \mathrm{m}^{2}$. Thermal conductivity of amorphous selenium is $0.13 \mathrm{~W} /(\mathrm{m} \cdot \mathrm{K})$ [11]. If we assume that a selenium island is a cube with side length equal to $1 \mu \mathrm{m}$ and that all energy $E$ is absorbed only on the island surface (both those assumptions can only increase the estimated temperature of the island), then at stationary conditions (when island temperature has already reached the maximum value) after elementary calculations we find that the change of island temperature is only $0.023^{\circ} \mathrm{C}$. This is a very insignificant change of temperature, therefore we can conclude that results obtained in this work are only caused by action of light.

During thermal evaporation of $\mathrm{Se}$, long polymer molecules of Se (rather than single atoms of Se) are ejected from the crucible. The length of those molecules can reach tens of atoms [10]. Such long molecules deposited on the substrate have low mobility and at layer deposition rate of $0.1-5 \mu \mathrm{m} / \mathrm{min}$ they form adsorbed gas, which can consist of several tens of monolayers [12]. Inside this adsorbed gas, polymer selenium molecules interact with each other, hence they do not evaporate from the substrate. Due to substrate defects or due to fluctuations in adsorbed gas, interaction between polymer selenium molecules in the adsorbed gas is stronger in some places. In those places, amorphous 
selenium islands begin forming (the smallest islands of amorphous selenium are not smaller than $25 \mathrm{~nm}$ [12]). Such mechanism of island formation is called ripening [13]. In this case, kinetics of diameter $d$ of a hemispherical island is of the following form [13]:

$$
d^{4}=C D_{\mathrm{s}} t,
$$

where $t$ is time, $D_{\mathrm{s}}$ is coefficient of surface diffusion of molecules, and $C$ is a constant depending on molecule size, density of adsorbed gas, surface tension of amorphous selenium layer, and sample temperature. Value of constant $C$ immediately after layer deposition is the same both for the illuminated layer and for the layer in the dark.

The dependence $d \sim t^{1 / 4}$ obtained in [14] confirms that the process of island formation after layer deposition is indeed ripening. Since islands are round, time dependence of the part of substrate filled with islands is $\sim t^{1 / 2}$. In our samples, Eq. (3) is only valid for the initial moments of time (immediately after layer deposition), when there are many adsorbed polymer selenium molecules on the substrate and there is no competition between individual islands. In later stages of island growth, the larger part of adsorbed gas will be already collected into islands and "competition" between islands will start: larger islands will consume smaller ones - this process is called Ostwald ripening [13]. Using Eq. (3) and Fig. 2(a), we determine that value of $D_{\mathrm{s}}$ after exposing the layer to light increases by a factor of 12. However, in the case of a thinner layer (Fig. 1(b)), the diffusion coefficient $D_{\mathrm{s}}$ does not change after exposure to light.

In order to understand why such action of light is only observed in layers with a larger amount of adsorbed gas, it is necessary to analyse influence of light on amorphous selenium molecules. It is known [15] that exposure of amorphous selenium layers to light stimulates growth of Se crystals in those layers. As shown in $[15,16]$, action of light does not break the bonds between selenium atoms in long selenium molecules, but those molecules are excited, hence polymer selenium molecules overcome the activation barrier and are attached to the growing crystal. It is likely that action of light does not cause dissociation of polymer selenium molecules in island-type layers, too (both in islands and in the adsorbed gas), but only excites those molecules. Quanta of light strike the entire layer surface uniformly. Immediately after layer deposition, islands take up a small part of the layer area (Figs. 1(b), 2(b)). Therefore, the number of molecules between islands is much larger than the number of molecules ad- jacent to the perimeter of the islands (the islands grow only by attaching the adjacent molecules of adsorbed Se gas). For this reason, uniform illumination of the layer causes preferential excitation of molecules that are relatively far away from the islands. However, when concentration of adsorbed molecules is small (as in a thin layer, e. g., $5 \mathrm{~nm}$-thick), interaction between individual molecules is weak, so that an excited molecule that is far away from an island can not transfer that excitation to a molecule that is near the island. Then the excess energy caused by action of light is transferred to the substrate and no changes in layer structure are observed (Fig. 1(b), initial moments of time). However, if a thick layer of adsorbed selenium gas is present (e. g., a $24 \mathrm{~nm}$-thick layer, which consists of at least 70 monolayers of adsorbed gas), then the layer will have a larger number of excited molecules in the adsorbed gas (since the layer of adsorbed gas is thicker); the excitation will be transferred further (e.g., an excited molecule on the surface will able to transfer its excess energy to the substrate only via intermediate molecules that are between the excited molecule and the substrate - hence excitation will spread out) and the distance between the point of excitation of an adsorbed gas molecule and the island will be smaller (since island concentration is much larger) than in the case of a thin layer. Therefore, after illumination of a thicker layer, mobility of the adsorbed gas in it increases ( $D_{\mathrm{s}}$ increases 12 times) and amorphous islands grow faster (Fig. 2(b), initial moments of time).

If an island-type selenium layer is exposed to light immediately after its deposition, then concentration of particles begins to decrease, because the smallest islands begin to disappear (Figs. 1(c) and 2(c)). Those islands do not contain a large amount of mass and they occupy a small area on the substrate. Therefore, those islands have no effect neither on layer thickness kinetics (Fig. 4) nor on layer filling kinetics (Figs. 1(a), 2(a)). Small islands, whose diameter is close to the critical diameter, balance on the verge of disappearance. Therefore, any additional energy given to such an island (e. g., an absorbed quantum of light) would stimulate its disappearance. In our opinion, this is the reason of disappearance of the smallest islands in the illuminated sample. Concentration of adsorbed gas decreases with time (because it is attached to the growing islands), whereas the critical diameter of a selenium island increases with time, because the critical diameter is inversely proportional to the amount of adsorbed gas [12].

When concentration of adsorbed gas decreases, the further evolution of the islands is determined by mass 
exchange between them (Ostwald ripening [13]). In this case, an important factor is the number of molecules that the islands are able to emit across their perimeter into the substrate. That number depends on the structure of the islands, too. It is known that light stimulates crystallization of amorphous selenium layers $[15,16]$. Therefore, it is reasonable to expect that light also stimulates polymerization of selenium molecules without crystal formation. In order for two molecules to stick together, their ends must be close to each other and their mobility must be limited [17]. Therefore, light stimulates polymerization of selenium molecules in islands, which have a relatively large density, rather than in adsorbed gas, which has a low density and large mobility. During polymerization, the size of molecules in the islands increases (i. e., the molecular mass $m$ increases). As a result, the flux $J_{\mathrm{v}}$ of molecules emitted from the island decreases [18]. The same conclusion follows from the Hertz-Langmuir-Knudsen equation [13]:

$$
J_{\mathrm{v}}=\frac{\alpha_{\mathrm{v}}\left(P_{\mathrm{E}}-P\right)}{\sqrt{2 \pi m k_{\mathrm{B}} T}},
$$

where $k_{\mathrm{B}}$ is the Boltzmann constant, $\alpha_{\mathrm{v}}$ is vaporisation coefficient, $P_{\mathrm{E}}$ is the equilibrium vapour pressure, $P$ is pressure of the gas of adatoms present on the substrate, $m$ is molecular mass, $T$ is temperature.

However, emission of molecules from the illuminated islands does not stop completely (otherwise island concentration in layers exposed to light would not change, but such change has been observed - Figs. 1(c), 2(c)). In this case, the molecules emitted from illuminated islands are larger than those emitted from islands in the dark (if long polymer molecules are only emitted from the crucible [10], then such long molecules, rather than individual atoms, must also be emitted from an island onto the surface of the substrate). Evaporation of such long molecules from the substrate is difficult [19], hence thickness of illuminated layers practically does not decrease during prolonged heating (Fig. 4, curves 1); this is the proof that light stimulates polymerization of molecules in the islands. The known fact that mass exchange between the islands takes place (in crystalline islands such mass exchange is absent, because they do not change even after exposure to an electron beam inside the electron microscope) together with results of investigations of electron diffraction in the islands (performed with the electron microscope) indicate that islands retain their amorphous structure in illuminated layers, too. Therefore, we conclude that light does not necessarily create crystals, but it can also stim- ulate polymerization of selenium molecules in amorphous islands.

A somewhat unexpected result is an increase of island concentration in a thin illuminated layer after 220 min (Fig. 1(c), curve 1). This could be caused by the fact that illuminated islands emit longer polymer molecules, which are less mobile due to their size, hence those molecules "collect" the remaining nearby molecules of adsorbed gas. Thus, new islands are formed. This process does not occur in thicker layers (Fig. 2(c), curve 1), because island concentration in those layers is almost 10 times higher than island concentration in thinner layers (Fig. 2(c), curve 1), so that thick layers do not have unoccupied areas needed for creation of new islands.

After exposure to light, mobility of selenium molecules increases not only in the adsorbed gas, but in a continuous layer, too. It is known [13] that a molecule, which has absorbed additional energy $E$, is able to diffuse an additional distance $r$ :

$$
r=1.26\left(\frac{E}{Q}\right)^{1 / 3} r_{s},
$$

where $E$ is the energy transferred to the molecule, $r_{s}$ is the radius of the molecule, $Q \approx 6.5 k_{\mathrm{B}} T_{\mathrm{m}}$ is the activation energy for admolecule diffusion, $T_{\mathrm{m}}$ is the melting temperature of the material.

It is known [11] that in the case of selenium $T_{\mathrm{m}}=$ $217.4{ }^{\circ} \mathrm{C}, Q=0.27 \mathrm{eV}$. If a molecule absorbs light with wavelength of 400-600 nm, then, according to Eq. (5), that molecule is able to diffuse an additional distance that is $2.8-2.5$ times larger than the radius of that molecule. Therefore, a continuous layer that is exposed to light transforms into an island-type layer faster than a layer that is kept in the dark (Fig. 3(b)).

\section{Conclusions}

After deposition of a thin amorphous selenium layer, the gas of adsorbed polymer selenium molecules forms on the substrate. Inside that gas, separate islands begin forming, i. e., the process called ripening takes place.

After exposure of an amorphous selenium layer to $1 \cdot 10^{6} \mathrm{~lx}$ flux of white light, the layer does not heat up, but a continuous layer transforms into an island-type layers faster and the mean thickness of an island-type layer increases faster.

The diffusion coefficient of molecules adsorbed on the substrate in the illuminated layers depends on light intensity and on thickness of the layer of adsorbed gas. In thick layers $(24 \mathrm{~nm})$, this diffusion coefficient can 
increase by a factor of 12 in comparison with diffusion coefficient of molecules in unexposed layers. In thinner layers $(5 \mathrm{~nm})$, light does not stimulate diffusion of adsorbed molecules, because the number of those molecules is small and their interaction is weak.

Light stimulates polymerization of amorphous selenium molecules that are either in islands or in the continuous layer. Emission of the resulting larger polymer molecules from the islands as well as evaporation of molecules that have been emitted across the island perimeter into the substrate is slower. Therefore, the mean thickness of illuminated layers (which is proportional to the total mass of the islands) does not decrease with heating. This property could be used for determination of the degree of polymerization of molecules inside the islands.

In the illuminated layers, islands continue to be amorphous.

In order to obtain a continuous layer of amorphous selenium with the minimum possible thickness, it is necessary to switch on illumination of the substrate and start deposition of the layer. Light must be switched off as soon as the layer becomes continuous.

\section{References}

[1] Z. Zhang and X. Yang, The effect of chain interpenetration on an ordering process in the early stage of polymer crystal nucleation, Polymer 47, 5213-5219 (2006).

[2] K.S.S. Harsha, Principles of Physical Vapor Deposition of Thin Films, 1st ed. (Elsevier Science, 2005).

[3] A.Yu. Menshutin, L.N. Shchur, and V.M. Vinokur, Probing surface characteristics of diffusion-limitedaggregation clusters with particles of variable size, Phys. Rev. E 75, 010401-1-4 (2007).

[4] L.S. Hunga and C.H. Chen, Recent progress of molecular organic electroluminescent materials and devices, Mater. Sci. Eng. R 39, 143-222 (2002).

[5] E. Montrimas and R. Rinkūnas, Phase composition of amorphous Se island layers, Lithuanian J. Phys 45, 263-266 (2005).

[6] Y. Ueda, M. Matsushita, S. Morimoto, J. Ni, H. Suzuki, and S. Mashiko, Structure and crystal growth of low molecular weight polyethylene vapor deposited on polymer friction-transferred layers, Thin Solid Films 331, 216-221 (1998).

[7] M. Goto, A. Kasahara, and M. Tosa, Growth of boron nitride nano islands on substrates, triggered by internal stress, Surf. Coatings Technology 168, 98-101 (2003).

[8] H. Ko and H. Lee, Fabrication of colloidal selfassembled monolayer (SAM) using monodisperse silica and its use as a lithographic mask, Thin Solid Films 447-448, 638-644 (2004).

[9] C.A. Poynton, Digital Video and HDTV: Algorithms and Interfaces (Morgan Kaufmann Publishers, Toronto, 2002).

[10] J.P. Audiere, C. Mazieres, and J.C. Carbales, Noncrystalline Se thin films deposited from controlled vapor-preparation, crystallization and optical properties, J. Non-Cryst. Solids 27, 411-419 (1978).

[11] Tables of Physical Quantities, ed. I.K. Kikoin (Atomizdat, Moscow, 1976) [in Russian].

[12] Br. Petretis and R. Rinkunas, The adatom density in discontinuous selenium films, Thin Solid Films 128, 269273 (1985).

[13] K.S. Sree Harsha, Principles of Physical Vapor Deposition of Thin Films (Elsevier, Amsterdam, 2006).

[14] Br. Petretis, R. Rinkunas, and V. Filipavicius, The mass transport mechanism in discontinuous selenium films, Thin Solid Films 85, 301-306 (1981).

[15] J. Dresner and G.B. Stringfellow, Electronic processes in the photo-crystallization of vitreous selenium, J. Phys. Chem. Solids 29, 303-311 (1968).

[16] H. Fiedler, J. Lauckner, and J. Finke, Photoinduzierte Phasenumwandlungen in Selenschichten, J. Signal 6, 467-473 (1978).

[17] L.H. Sperling, Introduction to Physical Polymer Science (John Wiley \& Sons, Hoboken, New Jersey, 2006).

[18] R.J. Beuhler, L.J. Greene, and L. Friedman, Solvated proton mass spectra of a tripeptide derivative, J. Am. Chem. Soc. 93, 4307-4312 (1971).

[19] R.J. Beuhler, E. Flanigan, L.J. Greene, and L. Friedman, Proton transfer mass spectrometry of peptides. A rapid heating technique for underivatized peptides containing arginine, J. Am. Chem. Soc. 96, 3990-3995 (1974). 


\title{
ŠVIESOS İTAKA AMORFINIO SELENO SLUOKSNIŲ STRUKTŪROS POKYČIAMS
}

\author{
E. Montrimas, R. Rinkūnas, S. Kuskevičius, R. Purlys
}

Vilniaus universiteto Fizikos fakultetas, Vilnius, Lietuva

\section{Santrauka}

Apšvietus amorfines seleno saleles $1 \cdot 10^{6} 1 \mathrm{x}$ šviesos srautu, jos netampa kristalinėmis, o išlieka amorfinès, tačiau šviesa skatina jose molekulių polimerizaciją. Dèl šios priežasties, kaitinant pavyzdèlị, apšviesto sluoksnio vidutinis storis nemažèja, o esančio tamsoje - mažèja. Apšviestas sluoksnis tampa vidutiniškai 3-4 kar- tus storesnis už esantį tamsoje. Taip pat ir užpildyta salelèmis padèklo dalis yra 1,5-2 kartus didesnè apšviestame sluoksnyje, negu esančiame tamsoje. Tačiau apšvietus ištisini sluoksnị, šis greičiau persitvarkys i salelinị. Taigi, norint pagaminti kuo plonesnį ištisini amorfinio seleno sluoksni, reikia apšviesti augimo metu tik tol, kol jis taps ištisiniu, o tada šviesą išjungti. 